\title{
Application of T-Wave Alternans in Evaluation of Prognosis in Patients with Intracerebral Hemorrhage
}

\author{
Xian Li, Xianglin Cheng* \\ Department of Neurology, The Clinical Medicine School of Yangtze University, The First Affiliated Hospital of Yangtze University, \\ Jingzhou, China \\ Email: ^45423626@qq.com
}

How to cite this paper: $\mathrm{Li}, \mathrm{X}$. and Cheng, X.L. (2017) Application of T-Wave Alternans in Evaluation of Prognosis in Patients with Intracerebral Hemorrhage. Yangtze Medicine, 1, 127-132.

https://doi.org/10.4236/ym.2017.13013

Received: May 19, 2017

Accepted: September 18, 2017

Published: September 21, 2017

Copyright ( $) 2017$ by authors and Scientific Research Publishing Inc. This work is licensed under the Creative Commons Attribution International License (CC BY 4.0).

http://creativecommons.org/licenses/by/4.0/

\section{(c) (i) Open Access}

\begin{abstract}
Objective: To explore the application value of electrocardiograph (ECG) T-wave Alternans (TWA) anomaly in acute stage of intracerebral hemorrhage patients. Methods: We choose 1175 intracerebral hemorrhage patients whose conventional 12-lead ECG has TWA in our hospital from January 2011 to December 2015, 751 patients without TWA in the same period as the control group, compared the volume of intracerebral hemorrhage, bleeding site and mortality between the 2 groups. Results: In TWA group, 247 cases died, 361 cases with massive intracerebral hemorrhage, 298 cases with brain stem hemorrhage; in TWA negative group (control group), 41 cases died, 93 cases with massive brain hemorrhage, 64 cases with brain stem hemorrhage. There are statistical differences between two groups $(\mathrm{P}<0.05)$. Multi factor Logistic regression analysis showed that massive intracerebral hemorrhage, brain stem hemorrhage, Glasgow score and TWA were the independent factors in the prognosis of intracerebral hemorrhage $(\mathrm{P}<0.05)$. Conclusion: The occurrence of TWA is significantly related to the volume of bleeding, the bleeding site and mortality, and can be used as an important parameter in the prognosis of intracerebral hemorrhage.
\end{abstract}

\section{Keywords}

Intracerebral Hemorrhage, T-Wave Alternans, Prognosis

\section{Introduction}

Intracerebral hemorrhage is a disease with high mortality. In cerebrovascular events, the ECG often changes, which is related to the high mortality of intracerebral hemorrhage. It can provide useful clues to the doctors to assess a patient 
and judge the prognosis. In addition to the general severity index, another indicator TWA, such as the S-T changes, severe arrhythmia and so on, can be a sign of myocardial repolarization abnormalities. Although we discussed the relationship between TWA and cerebral hemorrhage site and hemorrhage volume of 65 cases [1], the sample size is small, and it's not clear whether it can also be used as an indicator of prognosis of patients with cerebral hemorrhage. We did not explore, as we retrospectively analyze our hospital intracerebral hemorrhage patients in conventional 12 lead ECG TWA incidence and its relationship with prognosis from January 2011 to December 2015. We judge its value to evaluate the prognosis of intracerebral hemorrhage. Now it is reported as follows.

\section{Data and Methods}

\subsection{Case Selection}

First, 2417 intracerebral hemorrhage patients in our hospital were selected from January 2011 to December 2015, all patients were diagnosed as intracerebral hemorrhage by CT, excluding patients who had coronary heart disease (typical angina symptoms and ECG changes, or cardiac angiography evidence), arrhythmia (ECG changes), electrolyte disturbance (typical clinical symptom and blood electrolyte examination), cardiac hypertrophy (cardiac color ultrasound evidence), and used anti-arrhythmia drugs and digoxin drugs (patients readme). The remaining 1926 patients, including 1039 males and 887 females, aged 34 - 91 years, average age $(61.27 \pm 21.23)$ years. Among them, 1175 patients with the TWA were the experimental group, including 634 males and 541 females, aged 39 - 91 years, the average age $(63.75 \pm 20.17)$ years, Glasgow score $(9.1 \pm 2.1)$, of which 286 patients died, Glasgow score $(7.9 \pm 1.8)$; the remaining 751 patients as control group, including 405 males and 346 females, aged 34 to 87 years, average age $(60.32 \pm 22.74)$ years, Glasgow score $(12.3 \pm 4.1)$. There were no significant differences in age and sex between the two groups $(\mathrm{P}>0.05)$. The basic information between the experimental group and the control group is showed in Table 1.

\subsection{Method}

1) The Bleeding volume calculation: by coniglobus formula [2], select the maximum amount of bleeding plane according to the calculation, the volume of bleeding $(\mathrm{ml})=($ length $\times$ width $\times$ layer $) / 2$, the basal ganglia and lobe hemorrhage $>50 \mathrm{ml}$, cerebellar hemorrhage $>15 \mathrm{ml}$, the brain stem hemorrhage $>15$

Table 1. Comparison of basic information between the experimental group and the control group.

\begin{tabular}{cccccc}
\hline & Total & Average age & Gender male female & Glasgow score \\
\hline The experimental group & 1175 & $63.75 \pm 20.17$ & 634 & 541 & $9.1 \pm 2.1$ \\
The control group & 751 & $60.32 \pm 22.74$ & 405 & 346 & $12.3 \pm 4.1$ \\
P value & & $\mathrm{P}>0.05$ & $\mathrm{P}>0.05$ & $\mathrm{P}>0.05$ \\
\hline
\end{tabular}


$\mathrm{ml}$ are massive hemorrhage, the rest is not.

2) All intracerebral hemorrhage patients synchronous scanned routine 12-lead ECG examination on the $1^{\text {st }}$ day in hospital. TWA calculation: the same lead Twave amplitude difference $0.1 \mathrm{mv}$ is TWA, calculate the incidence of TWA.

\subsection{Statistical Analysis}

Intracerebral hemorrhage site, intracerebral hemorrhage volume and mortality between the two groups were compared by the $\chi^{2}$ test, using multiple factors logistic regression analysis to determine the independent predictive factor of prognosis, $\mathrm{P}<0.05$ has a statistically significant difference.

\section{Results}

1) In 1926 brain hemorrhage patients, 1175 cases with TWA, the occurrence rate was $61.0 \%, 454$ cases with massive brain hemorrhage, accounting for $23.6 \%$, 1472 cases without massive Intracerebral hemorrhage, accounting for 76.4\%; 96 cases with lobe hemorrhage, accounting for 5\%; 1272 cases with basal ganglia hemorrhage, accounting for $66.0 \%$; 173 cases with cerebellar hemorrhage, accounting for $9 \%$ and 362 cases with brain stem hemorrhage, accounting for 18.8\%, 23 cases with intraventricular hemorrhage, accounting for $1.2 \% ; 286$ cases died, accounting for $14.8 \%$.

2) Compared with the control group, in the experimental group, the patients with massive intracerebral hemorrhage, brain stem hemorrhage and death rate were statistically significant $(\mathrm{P}<0.01)$, as showed in Table 2 .

3) Multivariate logistic regression analysis showed that massive intracerebral hemorrhage, brain stem hemorrhage, Glasgow score and TWA were the independent factors in the prognosis of intracerebral hemorrhage $(\mathrm{P}<0.05)$.

\section{Discussion}

Intracerebral hemorrhage is a disease of high death rate and high disability rate [3]. Some patients did not die of primary brain dysfunction, but die of secondary cardiac causes, and this part of patients had no organic heart damage, but were secondary to intracranial damage. So those patients with coronary heart disease, arrhythmia, electrolyte disorder, cardiac hypertrophy, and the use of anti-arrhythmia

Table 2. Comparison between experimental group and control group in 1104 cases massive intracerebral hemorrhage patients, brain stem hemorrhage patients and death patients $(\mathrm{n}=1104)$.

\begin{tabular}{cccccc}
\hline & Total & $\begin{array}{c}\text { The experimental } \\
\text { group }\end{array}$ & $\begin{array}{c}\text { The control } \\
\text { group }\end{array}$ & $\begin{array}{c}\mathrm{X}^{2} \\
\text { value }\end{array}$ & P value \\
\hline Massive intracerebral hemorrhage & 454 & 361 & 93 & 85.539 & $<0.01$ \\
Brain stem hemorrhage & 362 & 298 & 64 & 85.125 & $<0.01$ \\
Death & 288 & 247 & 41 & 87.247 & $<0.01$ \\
Total & 1104 & 906 & 198 & & \\
\hline
\end{tabular}


drugs and digoxin drugs are excluded. We only analyze the influence on cardiac repolarization by intracerebral hemorrhage, and find an independent predictor of the prognosis with intracerebral patients hemorrhage. Because cardiac death is always caused by ventricular arrhythmias, and the influence of intracerebral hemorrhage on cardiac repolarization is obvious [4], repolarization abnormalities must lead to ventricular arrhythmia [5]. On the 12 lead ECG, the objective indicators are not much used to direct observe repolarization abnormalities, included heart rate variability, Q-T dispersion, TWA etc. The prediction effect of heart rate variability and Q-T dispersion has often been reported. Therefore, we mainly analyze the prediction function of the prognosis of intracerebral hemorrhage by TWA.

We retrospectively analyzed all patients who were hospitalized in our hospital from January 2011 to December 2015. The patients who had coronary heart disease, arrhythmia, electrolyte disorder, cardiac hypertrophy, and the use of anti-arrhythmia drugs and digoxin drugs were excluded. There were 1926 patients, in which 1175 patients had TWA on the conventional 12-lead ECG on the first day of admission, accounting for $61 \%$. There was a great difference between the reported normal healthy people [1], which further explained that intracerebral hemorrhage obviously has a direct impact on cardiac repolarization. And in intracerebral hemorrhage patients, the performance of the heart is significant and meaningful. At the same time, we analyzed the relationship between the TWA generator with the intracerebral hemorrhage site, the volume of intracerebral hemorrhage and the death time, and compared with the non TWA generator. In the experimental group, 247 patients died, accounting for $12.8 \%$; in the control group, 41 patients died, accounting for $2 \%$. They were statistically significant $(\mathrm{P}<0.05)$, further confirmed that the experimental group with TWA had a high mortality rate, at the same time we conducted a multifactor Logistic regression analysis, it showed that massive intracerebral hemorrhage, brain stem hemorrhage, Glasgow score and TWA were the independent factors for the prognosis of intracerebral hemorrhage, they could be used as a basis for judging the prognosis of intracerebral hemorrhage. But in our experiments we also found that in the experimental group, 361 cases with massive intracerebral hemorrhage, accounting for $18.7 \%$, 93 cases without massive intracerebral hemorrhage, accounting for $4.9 \%$; in the experimental group, 298 cases with brain stem hemorrhage, accounting for $15.5 \%$, in control group, 64 cases with brain stem hemorrhage, accounting for $3.3 \%$. The comparison between the two group was also statistically significant, it also showed that several predictive factors have a mutual influence on the occurrence mechanism. Massive intracerebral hemorrhage, brain stem hemorrhage could influence cardiac repolarization and lead to the occurrence of TWA.

The mechanism that intracerebral hemorrhage induces TWA is not very clear. Studies have found that the increase of sympathetic nerve tension can induce TWA, sympathetic nervous excitement makes the action potential morphology 
and amplitude change, thus inducing ventricular repolarization heterogeneity and leading to TWA. Therefore, we speculate that the mechanism of TWA in intracerebral hemorrhage is mainly caused by affecting the autonomic nervous function, which leads to the dysfunction of the sympathetic and parasympathetic. Autonomic nerve cortical representation known to regulate cardiac activity is in the orbital surface of the frontal lobe and the anterior cingulate cortex (i.e. 13 and 24 districts), and hypothalamus as a higher subcortical autonomic nerve center, regulates the cardiac activity. The insular lobe is closely related to the occurrence of TWA. Brain stem as the descending pathway of autonomic nerve, also has an important effect on the cardiac activity. So we speculate that massive intracerebral hemorrhage on the basal ganglia and lobes affect the autonomic nerve center of cingulate, insular lobe and hypothalamus. The brain stem hemorrhage can directly destroy autonomic nerve descending pathway, causing the change of autonomic nerve center and the imbalance of sympathetic and parasympathetic and affecting of cardiac conduction system and myocardial repolarization, producing TWA and leading to the occurrence of ventricular arrhythmia, but the specific mechanism needs to be further confirmed in our later experiments.

Our study has some limitations. First of all, a variety of other prognostic factors for intracerebral hemorrhage have been studied. However, in different models it is difficult to be fully taken into account, it may cause some deviation. We should try to judge comprehensively in the future analysis. Second, autonomic nerve dysfunction could be studied by other methods, such as the change of blood pressure and heart rate variability, but these studies need to observe for a long time and special analysis software, but our purpose is to provide a fast and effective prediction index to the grassroots medical staff, so we choose TWA, hoping to replace the application of heart rate variability and blood pressure changes. In short, TWA occurrence is an independent predictor of intracerebral hemorrhage patients' hospitalized death, TWA occurrence reminds that intracerebral hemorrhage patients have severe autonomic dysfunction and brain damage, these patients should get more attention in the follow-up treatment.

\section{Acknowledgements}

We thank the hospital medical records department's support in providing ECG information.

\section{References}

[1] Cheng, X.-L., Zhao, C.-S. and Ma, L. (2005) The Analysis of T Wave Alternations and QT Dispersion on Early Cerebral Hemorrhage Patient. Jilin Medicine, 26, 578-579.

[2] Xu, X., Chen, X., Zhang, J., Zheng, Y., Sun, G., Yu, X. and Xu, B. (2014) Comparison of the Tada Formula with software Slicer: Precise and Low-Cost Method for Volume Assessment of Intracerebral Hematoma. Stroke, 45, 3433-3535. https://doi.org/10.1161/STROKEAHA.114.007095

[3] Hemphill $3^{\text {rd }}$, J.C., Greenberg, S.M., Anderson, C.S., Becker, K., Bendok, B.R., 
Cushman, M., Fung, G.L., Goldstein, J.N., Macdonald, R.L., Mitchell, P.H., Scott, P.A., Selim, M.H. and Woo, D. (2015) Guidelines for the Management of Spontaneous Intracerebral Hemorrhage: A Guideline for Health Care Professionals from the American Heart Association/American Stroke Association. Stroke, 46, 2032-2060. https://doi.org/10.1161/STR.0000000000000069

[4] Junttila, E., Vaara, M., Koskenkari, J., Ohtonen, P., Karttunen, A., Raatikainen, P. and Ala-Kokko, T. (2013) Repolarization Abnormalities in Patients with Subarachnoid and Intraintracerebral Hemorrhage: Predisposing Factors and Association with Outcome. Anesthesia \& Analgesia, 116, 190-197.

https://doi.org/10.1213/ANE.0b013e318270034a

[5] Sachs, K.V., Harnke, B., Mehler, P.S. and Krantz, M.J. (2015) Cardiovascular Complications of Anorexia Nervosa: A Systematic Review. International Journal of Eat ing Disorders, 49, 238-248. https://doi.org/10.1002/eat.22481

\section{Submit or recommend next manuscript to SCIRP and we will provide best} service for you:

Accepting pre-submission inquiries through Email, Facebook, LinkedIn, Twitter, etc. A wide selection of journals (inclusive of 9 subjects, more than 200 journals)

Providing 24-hour high-quality service

User-friendly online submission system

Fair and swift peer-review system

Efficient typesetting and proofreading procedure

Display of the result of downloads and visits, as well as the number of cited articles

Maximum dissemination of your research work

Submit your manuscript at: http://papersubmission.scirp.org/

Or contact ym@scirp.org 